\title{
Disputa eleitoral e representação política na Região Metropolitana de São Paulo ${ }^{1}$
}

$\overline{\text { Frederica Valle de Queiroz Padilha }{ }^{2} \text { (i) }}$

\begin{abstract}
Este artigo analisa como a dinâmica política de representação pode se traduzir em obstáculos para a mobilização de atores políticos do Legislativo em torno de uma agenda metropolitana. Seu objetivo é verificar a representatividade dos deputados de base metropolitana na Assembleia Legislativa de São Paulo e caracterizar a disputa eleitoral nos municípios paulistas a partir de dois indicadores: um de concentração (número efetivo de candidatos) e um de competitividade (índice T). Os resultados apontam que os deputados metropolitanos paulistas não são subrepresentados na Assembleia e a disputa eleitoral nos municípios metropolitanos tende a ser menos concentrada, com um "efeito metrópole" sobre a concentração da disputa, mas não necessariamente mais competitiva.
\end{abstract}

Palavras-chave: disputa eleitoral; representação política; governança metropolitana; número de candidatos efetivos; índice T

\section{Introdução}

As questões ditas "metropolitanas" começaram a ganhar espaço no debate público a partir da década de 1950 com o acelerado crescimento urbano e o rápido processo de conurbação em torno das grandes cidades, evidenciando a necessidade de órgãos ou instrumentos de administração voltados para solução de problemas territoriais comuns. Contudo, a institucionalização das regiões metropolitanas só ocorreu em 1973, com a promulgação da Lei Federal Complementar no 14, quando foram instituídas as regiões metropolitanas de São Paulo, Belo Horizonte, Porto Alegre, Recife, Salvador, Curitiba, Belém e Fortaleza (Observatório das Metrópoles, 2009), com um modelo único de planejamento e gestão para todas elas.

Em 2019, segundo o IBGE, o país já contava com 74 regiões metropolitanas, áreas que continuam crescendo em número, magnitude e concentração de poder econômico. Cerca de $40 \%$ da população do Brasil e $50 \%$ do Produto Interno Bruto (PIB) estão

\footnotetext{
${ }^{1}$ Este artigo é parte da tese de doutorado "Representação política e governança na Região Metropolitana de São Paulo", apresentada ao Programa de Pós-Graduação em Planejamento Urbano e Regional da Universidade Federal do Rio de Janeiro - UFRJ, 2018.

2 Instituto de Pesquisa e Planejamento Urbano e Regional - UFRJ. Rio de Janeiro (RJ), Brasil.

E-mail: <frepadilha@hotmail.com>.
} 
concentrados em 15 regiões metropolitanas (IBGE, 2015). Só a Região Metropolitana de São Paulo (RMSP) concentra cerca de $19 \%$ do PIB e $10 \%$ da população brasileira. Dessa forma, como coloca Ribeiro (2004, p. 10): "qualquer estratégia de desenvolvimento está fortemente condicionada à capacidade da sociedade em enfrentar os desafios metropolitanos do crescimento".

Entretanto, muitos desses desafios ainda enfrentam obstáculos para serem abordados pela ótica metropolitana. O novo acordo político institucional da Constituição de 1988, por exemplo, trouxe uma concepção municipalista em que os arranjos políticos e territoriais passaram a privilegiar as escalas estadual e municipal, de modo que a escala metropolitana aparece como mais um ente de gestão governamental, sobrepondo-se ou superpondo-se aos já existentes. Nesse contexto, dar uma base política, administrativa e financeira às metrópoles por vezes é encarado como uma concorrência por recursos públicos e mesmo como uma ameaça à autoridade dos governos municipais e estaduais sobre seus territórios.

Dentro desse novo acordo, a criação e a gestão das regiões metropolitanas passaram a ser de responsabilidade dos estados por meio de suas Assembleias Legislativas. Assim, segundo Fernandes (2005, p. 13), é nesses espaços institucionais que deveriam ser discutidas e regulamentadas as propostas de gestão de problemas metropolitanos com uma base jurídica sólida, com legitimidade político-social e baseadas em arranjos institucionais de cooperação intermunicipal sustentáveis no longo prazo.

Nesse novo cenário, muitos estudos passaram a se voltar para nosso sistema de representação política para compreender a evolução, ou a não evolução, das questões metropolitanas. Nesse sentido, afirmam Carvalho e Corrêa (2012, p. 477):

Se um sistema de governança metropolitana parece decisivo, sobretudo, como forma de superação de dilemas de cooperação intermunicipal como saída para a provisão de bens públicos de caráter metropolitano, é razoável sugerir que o dilema da representação metropolitana deve ser analisado a partir da dinâmica político-eleitoral observada neste espaço.

É justamente nessa dinâmica político-eleitoral que Carvalho e Ribeiro (2013) indicam dois obstáculos para que as discussões sobre a solução de problemas metropolitanos prosperem. Considerando o princípio democrático one man, one vote, os autores apontam que os deputados de base eleitoral na metrópole seriam os representantes políticos com mais incentivos para abordar temas metropolitanos, e, assim, o primeiro obstáculo apontado pelos autores seriam as lacunas em termos da representatividade das cidades metropolitanas no Congresso e nas Assembleias Legislativas.

O segundo obstáculo concerne ao comportamento político das metrópoles, que seria regulado por gramáticas políticas distintas, em que a capital seria marcada por uma disputa mais competitiva e politizada, com maior número de votos em legendas 
partidárias, enquanto a periferia metropolitana se caracterizaria por uma disputa pouco competitiva, marcada pelo voto personalizado, em que os representantes metropolitanos tendem a obter a maioria de seus votos em apenas um município e, por essa razão, acabam voltando-se a assuntos locais e paroquiais em detrimento de temas que viabilizariam um programa metropolitano com foco na resolução de problemas comuns, gerando o que Carvalho (2009) chamou de "paroquialismo metropolitano":

Ora, se sabemos pela literatura voltada à análise da conexão eleitoral que a votação concentrada, numa ponta, gera comportamento paroquial, na outra ponta, poderíamos estar diante de fenômeno novo, não previsto pelo otimismo da velha sociologia eleitoral: um paroquialismo com base urbana. É de esperar que a ausência de temas metropolitanos da agenda pública tenha por raiz o que podemos chamar de paroquialismo metropolitano" (Carvalho 2009, p. 381)

Essas hipóteses estão ancoradas em parte na teoria da modernização, em que a associação de indicadores de desenvolvimento com o nível de democracia das sociedades é tema corrente. O livro O homem político (1967) de Seymour Lipset, por exemplo, aponta que a presença concomitante de aspectos como riqueza, urbanização, industrialização e educação estão diretamente associados à democratização.

Em sua teoria sobre poliarquia, Robert Dahl (1971) também aponta uma associação entre modernização - com a urbanização como parte desse processo - e sistemas políticos mais democráticos. Tendo essas associações como base, espaços mais urbanizados, como os espaços metropolitanos, têm sido caracterizados por possuir uma cultura política distinta da do clientelismo da política tradicional, com práticas mais horizontais e estruturas de poder mais plurais.

$\mathrm{Na}$ arena eleitoral, podemos pensar a relação entre espaços mais democráticos e modernização/urbanização a partir da hipótese segundo a qual em áreas com alta densidade populacional, como nas capitais e no seu entorno, não haveria ou haveria menos incentivos para um comportamento político guiado pela lógica do particularismo legislativo. Segundo Lamounier (1982), com o aumento do voto urbano a partir da década de 1930, estudos começaram a descrever esse voto como mais autêntico e ideológico do que os votos oriundos de áreas rurais e pequenos municípios.

No Brasil, estudos como o de Soares (1973) apresentam a dicotomia entre capital e interior em termos de cultura política e comportamento eleitoral como uma oposição de valores urbanos em relação aos rurais. Entre os primeiros prevaleceriam valores políticos e sociais mais universalistas em oposição a valores de natureza mais particularista identificados no interior. Como observa Carvalho (2012), nos termos da linguagem neoinstitucionalista e dentro da perspectiva da conexão eleitoral ${ }^{3}$, os deputados eleitos nas

3 Segundo esse modelo, o objetivo principal dos representantes é a reeleição, e, portanto, seu comportamento irá se orientar no sentido de atender sua clientela eleitoral. 
cidades com alto nível de urbanização, como as capitais, irão priorizar uma ação legislativa com um posicionamento em relação a temas de caráter universalista por meio de projetos de lei, pronunciamentos e ação legislativa de uma maneira geral, enquanto os deputados provenientes do interior tenderão a buscar recursos para suas respectivas localidades, pautando sua ação pela lógica do particularismo e do paroquialismo legislativo, quando os políticos têm um comportamento político voltado para atender a grupos de interesses, como seu reduto eleitoral. Cabe ressaltar ainda que, dada a importância socioeconômica das regiões metropolitanas acima destacadas, este artigo considera que os temas metropolitanos, como leis que regulam a gestão e organização dessas áreas, políticas de transportes e saneamento, entre outros, são de natureza universalista pois, mesmo que voltados para uma área específica (região metropolitana), influenciam, direta ou indiretamente, todo o estado.

A partir desse cenário e tendo como objeto de estudo a Região Metropolitana de São Paulo, este artigo tem como objetivo verificar a presença de uma subrepresentatividade de deputados metropolitanos na Assembleia Legislativa de São Paulo (Alesp) e as diferenças entre o comportamento político-eleitoral entre a capital e a periferia metropolitana a fim de refletir como esses mecanismos podem estar influenciando o avanço de uma agenda metropolitana no estado.

Para tanto, além desta "Introdução", o artigo apresenta mais duas partes. Na primeira, "A representação política da metrópole", será analisada a representatividade dos deputados de base metropolitana de acordo com a proporcionalidade de cadeiras desses deputados na Alesp. Na segunda, "A disputa eleitoral nos municípios paulistas", será analisado o nível de competitividade da disputa eleitoral dos municípios paulistas, com destaque para os municípios metropolitanos, a partir da hipótese de que, quanto maior a urbanização, maior a disputa eleitoral em uma localidade e, portanto, maior a probabilidade de encontrarmos uma pauta universalista, em que temas de natureza metropolitana estariam inseridos. Para a análise da disputa eleitoral nos municípios paulistas, serão utilizados dois diferentes indicadores: um índice de concentração da disputa (número efetivo de candidatos) e um índice de competitividade eleitoral (índice T). A última parte do artigo traz as "Conclusões" com algumas reflexões sobre a relação entre os resultados e o avanço de uma agenda metropolitana no estado.

\section{A representação política da metrópole}

Segundo Soares (2001, apud Carvalho, 2003), o nível de urbanização seria o fator central da dicotomia que distingue a disputa política entre as áreas rurais e as áreas urbanas do Brasil, sendo o primeiro caso caracterizado por valores clientelistas e paroquialistas e o segundo, por orientações mais universalistas:

Embora a urbanização se correlacione com a industrialização e muitas outras variáveis estruturais, as análises de regressão e correlação revelam que, 
eleitoralmente, a urbanização foi mais importante durante o período democrático - acima e além do desenvolvimento social (Soares, 2001, p. 187, apud Carvalho, 2003, p. 125).

Atualmente, ainda que estados como São Paulo possuam $96 \%$ de sua população em áreas urbanas, observamos que as diferenças socioeconômicas entre cidades mais ou menos populosas e urbanizadas ainda são presentes, o que também é válido para as cidades metropolitanas, que tendem a apresentar indicadores sociais mais altos, como mostram as Tabelas 1 e 2:

Tabela 1

Indicadores sociais: São Paulo - capital e cidades do estado de São Paulo por faixa populacional, 2010

\begin{tabular}{|l|c|c|c|c|c|}
\hline & $\begin{array}{c}\mathbf{N}^{\circ} \text { de } \\
\text { municípios }\end{array}$ & $\begin{array}{c}\text { IDHM } \\
\mathbf{2 0 1 0}\end{array}$ & $\begin{array}{c}\text { Renda per } \\
\text { capita }\end{array}$ & $\begin{array}{c}\text { Taxa de } \\
\text { analfabetismo na } \\
\text { população com mais } \\
\text { de 25 anos }\end{array}$ & $\begin{array}{c}\text { Taxa de } \\
\text { urbanização }\end{array}$ \\
\hline Capital & 1 & 0,81 & 1516 & 3,8 & 0,99 \\
\hline Acima de $200 \mathrm{mil}$ & 37 & 0,78 & 986 & 4,6 & 0,99 \\
\hline De 50 a $200 \mathrm{mil}$ & 85 & 0,77 & 888 & 5,9 & 0,94 \\
\hline De 20 a $50 \mathrm{mil}$ & 119 & 0,75 & 755 & 7,8 & 0,90 \\
\hline Até $20 \mathrm{mil}$ & 403 & 0,73 & 637 & 10,9 & 0,79 \\
\hline
\end{tabular}

Fonte: Atlas do desenvolvimento humano - PNUD (2010).

Tabela 2

Indicadores sociais: São Paulo - capital, regiões metropolitanas e interior, 2010

\begin{tabular}{|l|c|c|c|c|}
\hline & IDHM 2010 & $\begin{array}{c}\text { Renda per } \\
\text { capita }\end{array}$ & $\begin{array}{c}\text { Taxa de } \\
\text { analfabetismo na } \\
\text { população com mais } \\
\text { de 25 anos }\end{array}$ & $\begin{array}{c}\text { Taxa de } \\
\text { Urbanização }\end{array}$ \\
\hline Capital & 0,81 & 1516 & 3,74 & 0,99 \\
\hline RMSP (sem capital) & 0,76 & 817 & 6,44 & 0,98 \\
\hline $\begin{array}{l}\text { Região Metropolitana da Baixada } \\
\text { Santista (RMBS) }\end{array}$ & 0,76 & 846 & 5,77 & 0,99 \\
\hline $\begin{array}{l}\text { Região Metropolitana de Campinas } \\
\text { (RMC) }\end{array}$ & 0,77 & 992 & 5,81 & 0,98 \\
\hline Interior & 0,74 & 694 & 9,76 & 0,91 \\
\hline
\end{tabular}

Fonte: Atlas do desenvolvimento humano - PNUD (2010).

Assim, o primeiro aspecto da disputa eleitoral a ser investigado nesta seção são seus resultados em termos da representatividade das áreas metropolitanas dentro da Alesp. Assumindo-se a hipótese que associa o voto urbano a valores mais universalistas e o voto do interior a valores mais particularistas e considerando a temática metropolitana na primeira categoria de valores, pode-se supor que, quanto maior a presença de 
deputados de base metropolitana na assembleia, maiores são as chances de essa temática aparecer na agenda política.

Nesse sentido, os trabalhos de Aydos (1979) e Carvalho (2003) têm apontado que o que se verifica na Câmara e nas Assembleias dos estados é uma sub-representação dos deputados com base eleitoral nas capitais e regiões metropolitanas quando considerada a correspondência entre o número de representantes oriundos dessas zonas e o número de eleitores ali situados.

A RMSP possui 39 municípios e uma população de 21 milhões de habitantes (IBGE, 2015), concentrando $48 \%$ dos eleitores do estado. Assumindo-se que os representantes da capital ou metropolitanos são aqueles que obtêm pelo menos $50 \%$ de seus votos nessas regiões e dado que a Assembleia paulista elege 94 deputados, a RMSP precisaria eleger entre 45 e 46 deputados para ter uma justa correspondência entre eleitores e eleitos. Quando verificamos essa proporcionalidade para os pleitos a deputado estadual de 2002, 2006 e 2010, observamos um quadro "superavitário" de deputados metropolitanos (base na RMSP), como mostra a Tabela 3:

Tabela 3

Representação legislativa da RMSP na Assembleia - 2002/2006/2010

\begin{tabular}{|c|c|c|c|c|c|c|c|c|c|c|c|c|}
\hline \multirow{3}{*}{$\begin{array}{l}\text { Ano } \\
\text { eleição }\end{array}$} & \multicolumn{4}{|c|}{ Capital } & \multicolumn{4}{|c|}{ RM (sem a capital) } & \multicolumn{4}{|c|}{ Interior } \\
\hline & A & B & C & \multirow{2}{*}{$\begin{array}{l}\text { C-A } \\
\%\end{array}$} & A & B & C & \multirow{2}{*}{$\begin{array}{c}\text { C-A } \\
\%\end{array}$} & A & B & C & \multirow{2}{*}{$\begin{array}{l}\text { C-A } \\
\%\end{array}$} \\
\hline & $\begin{array}{c}\% \\
\text { eleitores } \\
\end{array}$ & \begin{tabular}{|c|}
$\begin{array}{c}\text { deputados } \\
\text { eleitos }\end{array}$ \\
\end{tabular} & $\%$ & & $\begin{array}{c}\% \\
\text { eleitores } \\
\end{array}$ & \begin{tabular}{|c|}
$\begin{array}{c}\text { deputados } \\
\text { eleitos }\end{array}$ \\
\end{tabular} & $\%$ & & \begin{tabular}{|c|}
$\%$ \\
eleitores \\
\end{tabular} & \begin{tabular}{|c|}
$\begin{array}{c}\text { deputados } \\
\text { eleitos }\end{array}$ \\
\end{tabular} & $\%$ & \\
\hline 2002 & 28 & 30 & 32 & 4 & 20 & 18 & 19 & -1 & 52 & 46 & 49 & -3 \\
\hline 2006 & 28 & 31 & 33 & 5 & 20 & 19 & 20 & 0 & 52 & 44 & 47 & -5 \\
\hline 2010 & 28 & 25 & 27 & -1 & 20 & 22 & 23 & 3 & 52 & 47 & 50 & -2 \\
\hline
\end{tabular}

Fonte: Elaboração própria a partir dos dados do Tribunal Regional Eleitoral de São Paulo - TRE-SP.

A Tabela 3 apresenta a proporção de eleitores de cada região (A), o número de deputados eleitos com a maioria dos votos provindos de cada região (B) e a porcentagem que esse número representa em relação ao total dos 94 deputados (C). Portanto, a coluna (C-A) mostra a porcentagem de deputados a mais ou a menos que a região elegeu em relação à proporção de eleitores ali residentes.

Os resultados referentes à capital mostram que, em 2002 e 2006, a cidade elegeu $4 \%$ e $5 \%$ a mais de deputados do que seria esperado caso a votação correspondesse exatamente ao tamanho do eleitorado. Nesses anos, os municípios da RMSP sem a capital tiveram uma representação proporcional ${ }^{4}$. No pleito de 2010, a capital apresentou uma representação proporcional, mas os municípios da RMSP sem a capital apresentaram 3\% a mais de deputados em relação ao seu eleitorado. Assim, quando consideramos a RMSP

${ }^{4}$ Como a Assembleia elege 94 deputados, cada deputado corresponde a mais de $1 \%$ de representação na Assembleia, de modo que um resultado de $1 \%$ para mais ou para menos não pode ser considerado como desproporcional. 
como um todo, observamos que a metrópole paulista tem apresentado um percentual superior de deputados eleitos do que seria esperado caso a votação fosse exatamente proporcional ao seu eleitorado.

Portanto, segundo os dados analisados nesta seção, no estado de São Paulo, a ausência de uma agenda política voltada para temas metropolitanos no Legislativo não parece estar relacionada a uma lacuna de deputados de base metropolitana na Assembleia. Uma outra hipótese, nesse caso, volta-se para o perfil geográfico de votação desses deputados.

Com foco na Região Metropolitana do Rio de Janeiro, Carvalho e Corrêa (2012) observaram que a votação da maioria dos deputados metropolitanos se concentra em apenas um município da região, ou mesmo em uma parte desses municípios - em particular, no caso da capital -, o que geraria mais incentivos para um comportamento legislativo paroquialista e, portanto, menos voltado para questões universalistas, nas quais se incluem os temas de natureza metropolitana. Contudo, como observa Carvalho (2003), no Brasil, a existência de um vetor distributivista - quando os políticos têm incentivos para atuar de modo a beneficiar sua base geográfica eleitoral - só se observa nos casos de deputados com distribuição geográfica de votos dominante (deputados que foram eleitos com a maioria dos votos de uma dada região ou município). Esse perfil geográfico é pouco observado em áreas metropolitanas, uma vez que seus municípios tendem a ser mais populosos. Além disso, em estudo sobre o perfil geográfico de votação dos deputados paulistas, Padilha, Ribeiro e Carvalho (2019) apontam que, no caso dos deputados metropolitanos, mesmo para aqueles com perfil dominante, esses incentivos não se realizam:

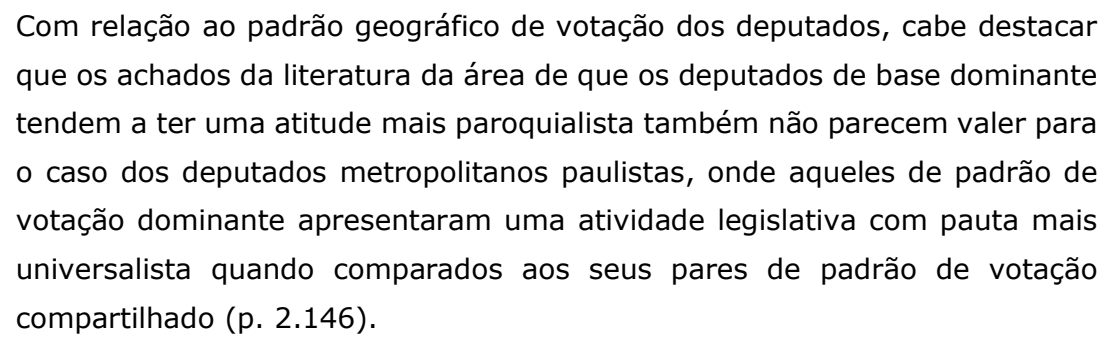

Dessa forma, conclui-se que, no caso da Assembleia Legislativa do Estado de São Paulo, os deputados de base metropolitana possuem um número proporcional, ou mesmo maior que o proporcional, de cadeiras quando considerado o número de eleitores da região, gerando um cenário em que temas metropolitanos teriam maior probabilidade de aparecer na agenda política.

\section{A disputa eleitoral nos municípios paulistas}

A disputa eleitoral tem sido abordada na literatura da sociologia política a partir da dinâmica de competitividade eleitoral, com foco na questão partidária e com grande 
influência do trabalho seminal de Maurice Duverger de 1951, por meio do qual ficou conhecida a "Lei de Duverger", que afirma que o sistema eleitoral majoritário conduz a um sistema bipartidário, enquanto o sistema de representação proporcional leva a um sistema multipartidário, que tem como consequência a fragmentação partidária. Embora essa fórmula tenha sido comprovada por diversos casos empíricos, Nicolau e Schmitt (1995) defendem que, para o caso brasileiro, os mecanismos do sistema eleitoral (fórmula e inclusão dos votos brancos no quociente eleitoral) combinados com a alta magnitude dos distritos brasileiros não favorecem os menores partidos, não sendo, portanto, a causa da fragmentação partidária.

No trabalho de Carvalho (2003), a dimensão individual da disputa eleitoral, com foco nos candidatos e não nos partidos, é extensamente investigada e a dinâmica da competição é abordada a partir da concentração eleitoral, com base na observação do número de candidatos que recebem votos de forma significativa em cada município. Seus resultados apontam que a maioria dos municípios brasileiros possui uma disputa eleitoral concentrada em poucos candidatos e portanto, segundo sua abordagem, pouco competitiva e com incentivos para uma prática política localista.

Podemos definir a disputa eleitoral como a competição por votos em uma determinada região ou município. Essa disputa pode ser influenciada por diversos fatores, como o contexto político do período da eleição (por exemplo, em função do desempenho dos políticos nos mandatos anteriores ou da forte influência de um líder popular), as características do próprio processo eleitoral e as características socioeconômicas e demográficas dos territórios de interesse.

Os fatores que influenciam a disputa eleitoral estão no centro de vários estudos e controvérsias. Para os autores que defendem o modelo distributivista - em que o principal interesse dos políticos é se reeleger, agindo em prol de seu eleitorado -, o sistema eleitoral brasileiro cria incentivos para que deputados atuem de forma a atender apenas seus redutos eleitorais, produzindo uma disputa menos competitiva nessas áreas. Para Figueiredo e Limongi (2008), críticos desse modelo, não há nenhuma razão institucional para afirmar que os deputados atuam para atender apenas uma determinada área do distrito eleitoral, e, além disso, um político não possuiria meios para impedir que outros busquem votos em áreas de seu interesse, sobretudo candidatos de outros partidos. Já para Avelino, Biderman e Silva (2011), outro fator importante é a influência dos resultados das eleições para prefeito no desempenho dos candidatos a deputado nas eleições dois anos seguintes. Ou seja, um candidato com um reduto eleitoral definido em alguns municípios veria a concorrência aumentar caso partidos de oposição ganhassem a prefeitura dessas cidades. A "rotatividade" de vagas em disputa também entra nos argumentos de Samuels (2003), uma vez que os deputados não permanecem em uma estratégia de carreira estática, mas manifestam preferência por cargos executivos, provocando o surgimento de oportunidades para que outros políticos se elejam deputados com os votos daquela região. 
Portanto, os inúmeros fatores que influenciam a disputa eleitoral fazem com que as formas de aferir dados e medidas sobre essa disputa ainda apresentem muitos limites metodológicos em função da dificuldade de mensurar e incorporar todos esses fatores nos modelos existentes.

Nesse contexto e apesar dele, uma das formas para medir essa disputa tem sido a utilização do número efetivo de partidos (NEP), de Laakso e Taagepera (1979). A finalidade do número efetivo de partidos é aproximar um número médio de partidos que competem pela maioria dos votos num determinado sistema partidário, facilitando assim a visualização do grau de concentração/fragmentação da competição em um determinado espaço. O número efetivo de partidos tem como base de cálculo o índice de concentração de Herfindal-Hirschman $(H H)$, que foi pensado para mensurar o grau de concentração/fragmentação de um determinado segmento de mercado entre as empresas concorrentes, levando-se em conta a fatia de mercado que cada uma das empresas domina. O índice $\mathrm{HH}$ é calculado tomando-se o somatório das proporções das fatias de mercado controladas por cada empresa de um determinado segmento. A sua fórmula é dada por $\sum p_{i}^{2}$, em que $p_{i}$ é a proporção de mercado controlada por cada empresa $i$, sendo que a elevação ao quadrado garante que as proporções não se anulem no somatório. 0 índice $H H$ varia entre 0 e 1 , quanto mais próximo de 1 for o resultado do índice, mais concentrado é determinado mercado.

A partir de uma adaptação desse índice, Carvalho (2003, 2009) utiliza como recurso metodológico o número efetivo de candidatos por município (NECm) para a análise da disputa eleitoral entre os candidatos a deputado federal. Segundo o autor, a finalidade do NECm é aproximar o número médio de candidatos que obtêm votação suficiente em determinado município para torná-los competitivos na disputa local.

O índice é calculado a partir da seguinte fórmula:

$$
N E C m=1 / \sum_{j=1}^{n} p_{i j}^{2}
$$

em que $p_{i j}$ é a proporção de votos de um candidato $j$ no município $i$; e $n$ é o número de candidatos que receberam pelo menos um voto nesse município $j$.

Entretanto, a utilização do NECm para medir a competitividade da disputa eleitoral encontra alguns críticos como Silva (2013). Com o mesmo objetivo, o autor defende e utiliza o índice de desequilíbrio proposto por Taagepera (1979), que, ao avaliar a relação entre cada par de observações simultaneamente, se concentra nas diferenças entre os tamanhos relativos da votação em cada candidato, sendo essa uma característica desejada para um índice de competitividade eleitoral. Dessa forma, quanto menor a margem de votos obtida pelos candidatos mais votados em relação aos demais, mais competitiva a eleição naquela localidade.

A fórmula para essa medida pode ser descrita pela seguinte expressão: 


$$
T_{m}=\frac{\sum_{i=1}^{\infty}\left[\frac{\left(P_{i, m}-P_{i+1, m}\right)}{i}\right]-H_{m}^{2}}{\sqrt{H_{m}}-H_{m}^{2}}
$$

em que $T$ é índice de desequilíbrio para a cidade $m, P$ é o percentual de votos do $i$-ésimo candidato na cidade $m$ e $H$ é o índice Herfindahl-Hirschman na cidade $m$. Os candidatos devem ser ordenados e o índice está restrito ao intervalo entre 0 e 1 (o último termo é $\mathrm{i}=$ $0)$, mostrando o nível de disputa eleitoral na cidade. O termo $H$ é incluído, segundo Taagepera, como uma forma de eliminar a "correlação residual" com o próprio termo $H$, já que o somatório do numerador varia entre $\sqrt{H}$ e $H^{2}$.

Considerando-se os votos recebidos pelos diversos candidatos, quanto maior 0 valor do índice, mais desequilibrada é a distribuição de votos em determinado município, ou seja, menos acirrada é a disputa, uma vez que algum candidato desequilibrou a eleição em seu favor. Assim, o nível de competição de um município qualquer está inversamente relacionado ao resultado do índice: quanto mais próximo a 0, maior é a competição (Silva, 2013, p. 411). O autor argumenta ainda que o indicador proposto tem a capacidade de avaliar casos extremos de forma adequada, sendo um indicador relevante para avaliar os níveis de competição eleitoral em qualquer localidade:

Se aplicado a um caso em que determinado candidato obtém $100 \%$ dos votos, o valor observado pelo índice T será igual a um. Por outro lado, se os candidatos dividirem igualmente os votos, o valor observado será igual a zero. Esta característica é desejável, uma vez que aponta sua capacidade em alcançar casos extremos, mesmo que não se espere que aconteçam (Silva, 2013, p. 412).

Como o foco deste artigo é investigar as características da disputa eleitoral na RMSP, os dois índices foram calculados e analisados, a fim de um melhor entendimento sobre essa disputa e suas particularidades em relação aos outros municípios. Os Gráficos 1 e 2 mostram a distribuição de cada índice em cada um dos pleitos analisados: 
Gráfico 1

Distribuição do NECm em 2002, 2006 e 2010

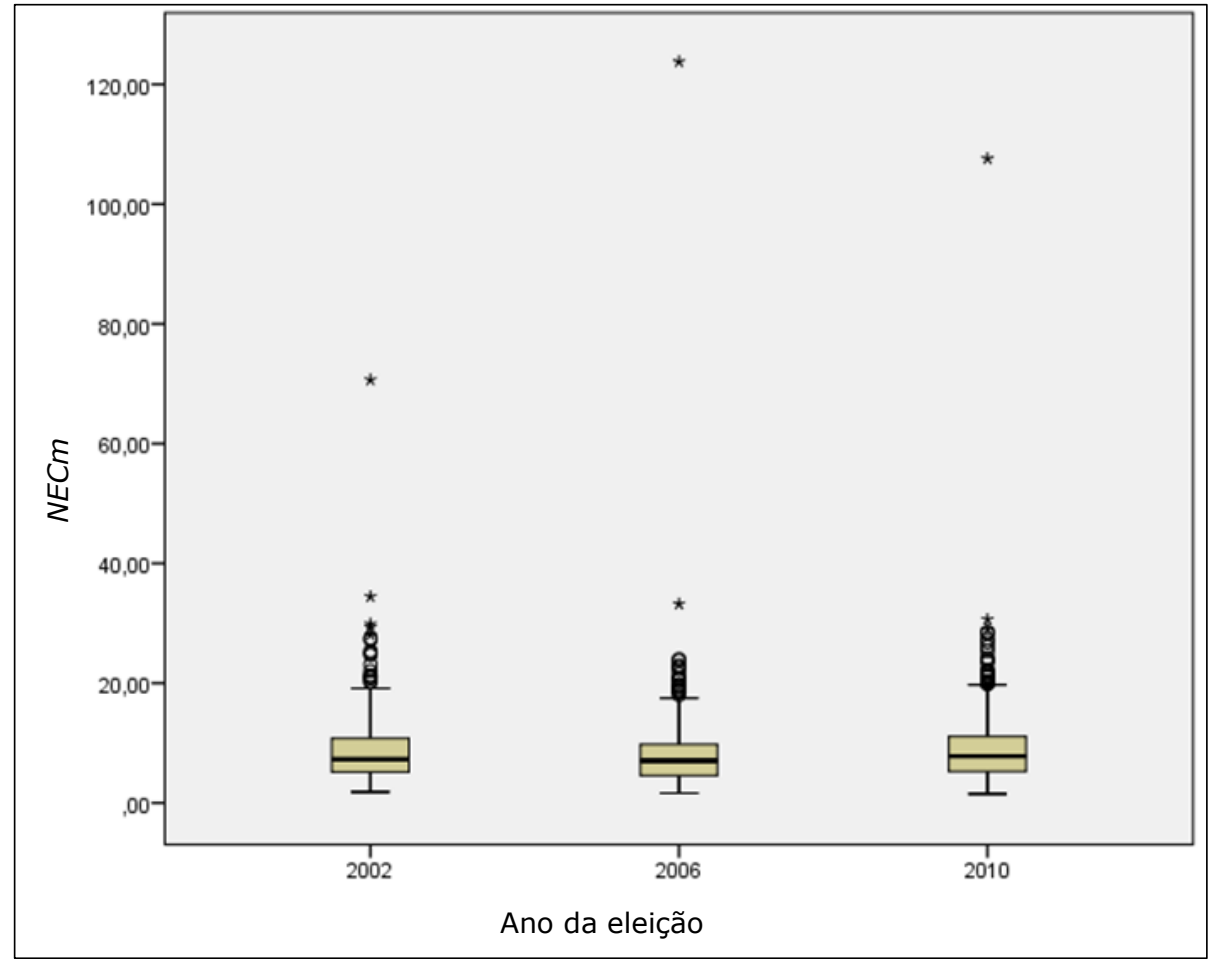

Fonte: Elaboração própria com base em dados do TRE-SP. 
Gráfico 2

Distribuição do índice T em 2002, 2006 e 2010

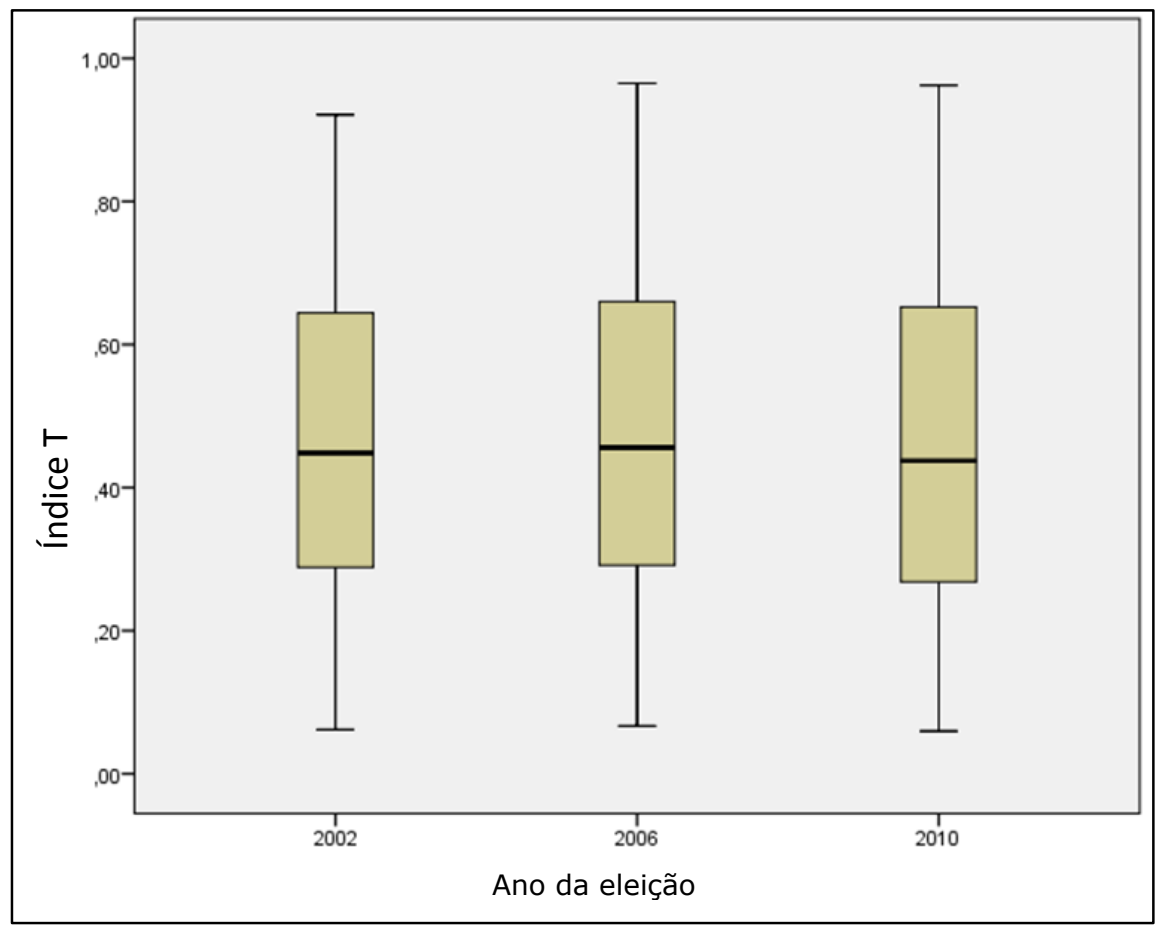

Fonte: Elaboração própria com base em dados do TRE-SP.

A distribuição do $N E C m$, ilustrada no Gráfico 1, mostra que a mediana e o NECm mínimo se mantêm relativamente próximos nos três pleitos analisados (mediana em torno de 7,5 e NECm mínimo em torno de 1,7). Já a parte superior da distribuição apresenta vários casos acima do limite superior, indicando um grande número de casos atípicos, que correspondem, em sua maioria, a municípios populosos e localizados em regiões metropolitanas. Destaca-se no gráfico o NECm máximo e sua diferença entre os pleitos de 2002 e 2006, sendo 70 no primeiro e 123 no segundo, uma variação de 53 candidatos efetivos.

O NECm máximo é sempre aquele que se refere à capital paulista, e seu baixo valor em 2002 em relação aos outros anos pode ser explicado pela expressiva votação da candidata Havanir (Prona) na capital, o que aumentou a concentração da disputa: em 2002 a deputada obteve mais de $8 \%$ dos votos da capital, mais que o dobro do segundo candidato, que obteve pouco mais de $3 \%$, uma diferença de 5 pontos percentuais. Para uma comparação, em 2010 a diferença entre os dois candidatos mais votados na capital foi de apenas 0,3 ponto percentual. O caso de Havanir foi influenciado pelo "fenômeno Enéas", o candidato federal mais votado da história nesse mesmo pleito. Já na eleição de 2006, apesar de a capital paulista exibir o maior NECm entre os pleitos analisados, esse 
índice apresenta a menor média $(7,88)$, indicando que esta parece ter sido uma eleição mais "concentrada" em termos do número efetivo de candidatos.

Já a distribuição do índice de equilíbrio T (Gráfico 2) mostra uma maior estabilidade entre os pleitos, sendo que sua mediana é maior em 2006, assim como sua média $(0,48)$, o que indica que essa eleição, além de ter sido a mais concentrada, foi também a menos competitiva em relação aos outros pleitos analisados. Esses resultados condizem com os achados do próprio Silva (2013) em sua análise da votação para deputado federal no país. Ainda que esses estudos não tenham se aprofundado sobre as causas desse cenário mais concentrado e menos competitivo em 2006, o fato de ele ocorrer de modo generalizado no país e se repetir em eleições para diferentes cargos (Câmara Federal e Assembleia Legislativa de São Paulo) sugere a influência de fatores macros ligados ao sistema eleitoral e ao contexto político sobre o índice, como o fato de ser uma eleição em que um presidente com alta popularidade estava concorrendo à reeleição.

Os índices apresentam uma correlação negativa (quanto maior a concentração, menor a competição), mas essa correlação não é considerada forte $(-0,49)$. Ou seja, muitos municípios com alto NECm, ou com uma disputa eleitoral concentrada em poucos candidatos, apresentam um baixo índice T, ou uma disputa muito competitiva, e viceversa. Com efeito, as análises feitas por Carvalho (2003) do NECm dos municípios brasileiros nas eleições para a Câmara Federal de 1994 e 1998 apontam que as regiões Norte e Nordeste apresentam uma disputa eleitoral mais concentrada em menos candidatos quando comparadas às regiões Sul e Sudeste. Já em sua análise do índice T, também para Câmara Federal nas eleições de 1994 a 2010, Silva (2013) demonstra que a região Sudeste é a menos competitiva em todos os pleitos analisados: "nota-se também que, contrariamente à tese dos grotões, a região Sudeste é sistematicamente a menos competitiva, enquanto a Norte, a mais" (p. 414).

Nos pleitos analisados neste artigo, novamente o caso da capital paulista se destaca. No ano de 2002, com mais de 70 candidatos efetivos, São Paulo apresenta a disputa menos concentrada do estado (o segundo município com a disputa menos concentrada é Arujá, com um NECm de 34). Nesse mesmo ano, quando observamos o índice $T$ para a capital, temos um resultado de 0,49 , índice maior (menos competitivo) do que a média do restante dos municípios paulistas, pois, como anteriormente demonstrado, nessa eleição a candidata Havanir obteve mais que o triplo de votos do que o segundo candidato mais votado na capital. Esse exemplo demonstra a alta importância que o índice $T$ tende a dar para a diferença entre o primeiro e o segundo lugar.

Contudo, apesar das diferenças regionais observadas, os estudos realizados no âmbito da Câmara Federal utilizando tanto o NECm como o índice $\mathrm{T}$ têm apontado que, no geral, as capitais dos estados tendem a apresentar uma disputa eleitoral diferenciada: menos concentrada no caso do NECm e mais competitiva no caso do índice T. 
Considerando a média do NECm de todos os municípios do estado de São Paulo, em todos os pleitos analisados $(8,45)$, tem-se que $60 \%$ dos municípios apresentam NECm abaixo da média, caracterizando um quadro geral de alta concentração de votos entre os municípios do estado de São Paulo. No entanto, cabe destacar que, quando comparado aos índices dos outros estados do país, o estado de São Paulo tende a apresentar uma disputa menos concentrada, como mostra Carvalho (2003, p. 72). Em sua análise das eleições de 1994 e 1998 para deputado federal, a média do NECm dos municípios do país foi de 5,6, enquanto o NECm médio dos municípios do estado de São Paulo foi de 9,2.

A Tabela 4 evidencia que, além da capital, os municípios das regiões metropolitanas analisadas (RMSP, RMC - Região Metropolitana de Campinas - e RMBS - Região Metropolitana da Baixada Santista) também apresentam uma média de NECm maior do que os municípios do interior em todos os pleitos. Isso indica que, além das características do próprio processo eleitoral e do contexto político, alguns fatores inerentes às regiões metropolitanas parecem ter influência sobre a concentração da disputa eleitoral no interior desses municípios, fatores esses que serão investigados a seguir.

Tabela 4

Número efetivo de candidatos por município (NECm) para as eleições a deputado estadual de São Paulo por região

\begin{tabular}{|l|c|c|c|c|}
\hline & & $\mathbf{2 0 0 2}$ & $\mathbf{2 0 0 6}$ & $\mathbf{2 0 1 0}$ \\
\cline { 2 - 5 } & Total de candidatos & 1420 & 1506 & 1542 \\
\cline { 2 - 5 } & Total de partidos & 30 & 28 & 26 \\
\hline \multirow{3}{*}{\begin{tabular}{l} 
Média do \\
número \\
efetivo de \\
candidatos \\
\cline { 2 - 5 }$(N E C m)$
\end{tabular}} & RMSP (sem a capital) & 13,7 & 11,8 & 12,8 \\
\cline { 2 - 5 } & RMBS & 13,9 & 14,6 & 17,3 \\
\cline { 2 - 5 } & RMC & 10 & 9,5 & 9,9 \\
\cline { 2 - 5 } & Interior & 7,9 & 7,2 & 8,4 \\
\cline { 2 - 5 } & Média & 8,5 & 7,9 & 8,9 \\
\hline
\end{tabular}

Fonte: Elaboração própria a partir de dados do TSE.

Fatores que influenciam a concentração da disputa eleitoral medida pelo NECm

A partir da análise da eleição para deputado federal em 1998, Carvalho (2003) aponta uma correlação significativa entre $N E C m$, variáveis socioeconômicas e número de eleitores de cada município, sugerindo que, quanto maior e mais desenvolvido for o município, menos concentrada é a disputa eleitoral e, portanto, maior é o $N E C m$, ou 
"quanto mais pobre um dado distrito, maior a probabilidade de a competição ali ser concentrada em poucos candidatos" (Carvalho, 2003, p. 89).

Para as eleições a deputado estadual paulista, essa hipótese será testada a partir de variáveis socioeconômicas e demográficas dos municípios, a fim de verificar se há alguma relação entre elas e o NECm destes. Como anteriormente ressaltado, a diferença do NECm em um mesmo município ao longo dos pleitos analisados explicita a importância de variáveis relacionadas ao próprio processo eleitoral como variáveis explicativas do NECm. A presença de candidatos que são liderança em certos municípios, por exemplo, aumenta a concentração da disputa nessas localidades em torno deles. Como Ames (2003, p. 83) destacou em suas análises para a Câmara Federal: "as características políticas dos municípios são muito mais importantes do que os aspectos econômicos e demográficos". No entanto, não foram encontrados dados disponíveis para as eleições a deputado estadual que pudessem representar aspectos do sistema político-eleitoral dos municípios ${ }^{5}$.

No estudo de Silva (2013) é elaborado um modelo eleitoral que utiliza como variáveis "políticas" algumas variáveis relacionadas ao tamanho dos estados, como o número de municípios por estado e a relação entre a população e o número de deputados que o estado elege. Essas variáveis, no entanto, não servem para o modelo proposto neste artigo, uma vez que este analisa as eleições para deputado estadual do estado de São Paulo. Portanto, o modelo proposto irá examinar apenas o efeito das variáveis socioeconômicas e demográficas dos municípios sobre a concentração da disputa eleitoral, uma vez que, em outros trabalhos (Carvalho, 2003), foram encontradas relações significativas entre essas variáveis.

Foram escolhidas variáveis socioeconômicas que representam diferentes aspectos dos municípios e que apresentaram correlação significativa com os índices de concentração e competitividade eleitoral utilizados. As variáveis utilizadas foram: população (POP), taxa de analfabetismo da população com mais de 25 anos (T_ANALF), desigualdade de renda medida pelo índice de Gini, renda per capita (RDPC), taxa de urbanização (T_URB) e produto interno bruto municipal (PIB).

Primeiramente, para medir o grau e a direção da correlação entre duas variáveis, foi utilizado o coeficiente de correlação de Pearson, que varia entre 1 e -1 , sendo que, quanto mais próximo de 1 ou -1 , maior é a correlação (positiva ou negativa) entre as variáveis. Quanto mais próximo de 0 , menor a correlação. É considerada alta uma correlação maior que 0,6. Essa análise também é necessária para detectar uma possível alta correlação entre as variáveis explicativas, o que pode gerar problemas de multicolineariedade no modelo. Os resultados, expostos na tabela do Apêndice 1, mostram que todas as variáveis são correlacionadas com o NECm. No entanto, algumas das variáveis explicativas são altamente correlacionadas entre si como a RDPC com a T_ANALF e o PIB com a POP (destacadas na tabela). Dessa forma, optou-se por utilizar a variável que

\footnotetext{
${ }^{5}$ Foram solicitados, por e-mail, dados a respeito da residência dos candidatos, pois esses dados não estão disponíveis nas bases do TRE-SP, mas não houve resposta.
} 
apresentou a maior correlação, de modo que as variáveis T_ANALF e o PIB foram descartadas do modelo.

Foi realizado igualmente o controle das variáveis atípicas (outliers), notadamente os valores relativos à capital. Para tanto, optou-se pela utilização de uma variável binária (dummy) para São Paulo, assim como outras duas variáveis binárias para os outros municípios da RMSP e para os municípios das RMC e RMBS (RMCBS). Foi aplicado então um modelo estatístico de regressão múltipla com as variáveis selecionadas. A forma funcional geral do modelo é dada pela expressão:

$$
\begin{gathered}
N E C_{m t}=\beta_{1}+\beta_{2} P O P_{m t}+\beta_{3} G I N I_{m t}+\beta_{4} R D P C_{m t}+\beta_{5} T_{-} U R B_{m t}+\beta_{6} \text { DummyCapital }+ \\
\beta_{7} \text { DummyRMSP }+\beta_{8} \text { DummyRMCBS }+\beta_{9} \text { Dummy } 2006+\beta_{10} \text { Dummy } 2010
\end{gathered}
$$

em que a variável dependente do modelo é o $N E C m$ no município $m$ no ano eleitoral $t$, e como variáveis independentes, as variáveis anteriormente descritas.

Os resultados das estimativas estão na Tabela 5 : 
Tabela 5

Estimativas dos parâmetros do modelo de regressão múltipla: variável dependente $\mathrm{NECm}$

\begin{tabular}{|c|c|c|}
\hline \multicolumn{3}{|c|}{ NEC } \\
\hline & Modelo 1 & Modelo 2 \\
\hline C & $\begin{array}{c}4,57 * * * \\
(1,27)\end{array}$ & $\begin{array}{c}5,04 * * * \\
(1,26)\end{array}$ \\
\hline POP & $\begin{array}{c}8,551 \mathrm{E}-6 * * * \\
(0,00)\end{array}$ & $\begin{array}{c}9,638 \mathrm{E}-7 \\
(0,00)\end{array}$ \\
\hline Gini & $\begin{array}{c}7,19 * * * \\
(1,15)\end{array}$ & $\begin{array}{c}7,04 * * * \\
(2,16)\end{array}$ \\
\hline RDPC & $\begin{array}{c}0,002 * * * \\
(0,001)\end{array}$ & $\begin{array}{c}0,002 * * \\
(0,001)\end{array}$ \\
\hline T_URB & $\begin{array}{c}0,10 \\
(0,008)\end{array}$ & $\begin{array}{c}0,08 \\
(0,008)\end{array}$ \\
\hline Dummy_Capital & & $\begin{array}{c}82,63 * * * \\
(13,16)\end{array}$ \\
\hline Dummy_RMSP & & $\begin{array}{c}4,74 * * * \\
(0,48)\end{array}$ \\
\hline Dummy_RMCBS & & $\begin{array}{c}3,52 * * * \\
(0,54)\end{array}$ \\
\hline Dummy_2006 & $\begin{array}{l}-0,32 \\
(0,27)\end{array}$ & $\begin{array}{l}-0,37 \\
(0,27)\end{array}$ \\
\hline Dummy_2010 & $\begin{array}{c}1,07 * * * \\
(0,333)\end{array}$ & $\begin{array}{l}1,02 * * * \\
(0,325)\end{array}$ \\
\hline $\mathrm{R}^{2}$ & 0,395 & 0,433 \\
\hline No de observações & 1935 & 1935 \\
\hline
\end{tabular}

Fonte: Elaboração própria a partir dos dados do TRE-SP e do Atlas de Desenvolvimento Humano - PNUD 2010.

Erros-padrão entre parênteses. ${ }^{* * *} p<0,01, * * p<0,05, * p<0,10$

Os resultados mostram que a população, o índice de Gini e a renda per capita (RDPC) se mostram correlacionados de forma significativa com o número de candidatos efetivos. Contudo, no segundo modelo, a inclusão das variáveis dummies para a capital e para as regiões metropolitanas rouba todo o efeito da variável relativa à população dos municípios, enquanto o Gini e a RDPC se mostram significantes em ambos os casos. No caso do Gini, o sinal da variável de resposta é positivo, ou seja, quanto maior a desigualdade, maior a dispersão de votos. Uma possibilidade de interpretação desse resultado é que a desigualdade de renda de diferentes camadas da população se reflita em 
desigualdade de preferências eleitorais; no entanto, essa hipótese precisaria ser mais bem investigada.

$\mathrm{O}$ aumento do $\mathrm{R}^{2}$ entre os dois modelos (que também ocorre no caso do $\mathrm{R}^{2}$ ajustado, que vai de 0,395 para 0,433) aponta uma melhora no poder explicativo do modelo com a adição das dummies de pertencimento a uma RM. No entanto, embora o $\mathrm{R}^{2}$ tenha um valor relativamente alto, esses resultados devem ser lidos com parcimônia e outras investigações precisariam ser realizadas para uma melhor compreensão da relação entre a concentração da disputa eleitoral e os municípios metropolitanos, considerando por exemplo, uma amostra nacional.

Chama a atenção ainda que a taxa de urbanização, tão cara à teoria da modernização, não se mostre significativa nos dois modelos. Já as variáveis relativas à capital e às RMs se mostram significativas a um nível de confiança de $99 \%$, indicando que os municípios metropolitanos, sobretudo a capital paulista, apresentam uma disputa eleitoral mais dispersa (menos concentrada) que o restante dos municípios, e esse fato parece estar associado a fatores relativos a sua condição metropolitana, o que sugere algum tipo de "efeito metrópole" que se correlaciona positivamente com o nível de dispersão da disputa eleitoral medido pelo NECm.

O segundo modelo destaca igualmente que o valor do coeficiente da variável dummy_RMSP é maior do que o da variável dummy_RMCBS, ainda que, no primeiro caso, a capital esteja excluída, enquanto, no último, as cidades polos Campinas e Santos façam parte da amostra, evidenciando a importância da RMSP em relação a outras RMs do estado.

O estudo de Nunes, Chaia e Sanches (2012), que investiga a cultura política e os valores de cidadania na RMSP, fornece pistas importantes sobre esse possível "efeito metrópole". Os autores partem da abordagem clássica e de natureza sociológica que relaciona o desenvolvimento econômico e a urbanização à cultura política, mas também trabalham com a hipótese de que essa cultura é influenciada pela história política local e sua relação com o contexto nacional, levando em consideração o eventual impacto da vida metropolitana sobre o efetivo exercício do direito da cidadania política. Primeiramente, os dados levantados mostram que as cidades metropolitanas analisadas ${ }^{6}$, quando comparadas à média nacional, apresentam níveis mais elevados de socialização, interesse pela política, associativismo, mobilização e exposição à mídia e similares, comportamentos

\footnotetext{
${ }^{6}$ Barueri, Carapicuíba, Diadema, Guarulhos, Itapevi, Itaquaquecetuba, Mairiporã, Osasco, Ribeirão Pires, Santo André, São Bernardo do Campo, São Caetano do Sul e São Paulo.
} 
que são exponenciados na capital e indicam um maior acesso dessa população a recursos que favorecem o fortalecimento de uma cultura política:

De imediato pode-se vincular a mídia à política, uma vez que estes meios e principalmente a imprensa escrita exercem um papel fundamental nas sociedades democráticas, pois, além de se constituírem em agentes/atores, são tanto formadores quanto veículos de expressão da opinião pública (Nunes, Chaia e Sanches, 2012, p. 343).

As tendências descritas acima podem ser parte dos mecanismos que produzem o "efeito metrópole", que se mostra como um fator correlacionado ao nível de concentração da disputa eleitoral para deputado estadual nos municípios paulistas.

Já Carvalho e Corrêa (2012), com foco na Região Metropolitana do Rio de Janeiro, procuraram compreender como esse "efeito metrópole" ocorre dentro do perímetro metropolitano a partir da hipótese de que os legisladores (deputados) não teriam incentivos em apoiar uma agenda pública de natureza metropolitana em função da distribuição de suas votações no interior desse espaço. Os autores analisaram o número efetivo de candidatos usando como unidade territorial "áreas de ponderação" utilizadas no Censo Demográfico de 2000 (IBGE), que, no geral, coincidem com os limites dos bairros do município do Rio de Janeiro e com os limites municipais da periferia metropolitana. Os resultados mostraram que os locais de votação com uma disputa mais concentrada em poucos candidatos tinham uma ocorrência maior nos municípios do entorno metropolitano, enquanto a ocorrência de locais com votação mais dispersa aumentava no município do Rio de Janeiro, sobretudo nas áreas mais centrais.

Resultado análogo foi observado para o universo dos candidatos a deputado estadual no pleito de 2006 dentro da RMSP7. Os autores calcularam o NECm para cada local de votação e, a partir da distribuição territorial do NECm nos locais de votação, foi realizada uma classificação das áreas internas da região metropolitana, utilizando-se um procedimento de cluster em quatro categorias: concentração alta; concentração média; dispersão média; dispersão alta. O resultado pode ser visto no Mapa 1:

\footnotetext{
${ }^{7}$ Resultados do relatório de pesquisa Geografia do voto para deputados estaduais nas áreas intraurbanas da Região Metropolitana de São Paulo do Observatório das Metrópoles (não publicado).
} 


\section{Mapa 1 \\ Áreas de votação segundo o grau de competitividade por votos para deputado estadual - 2006}

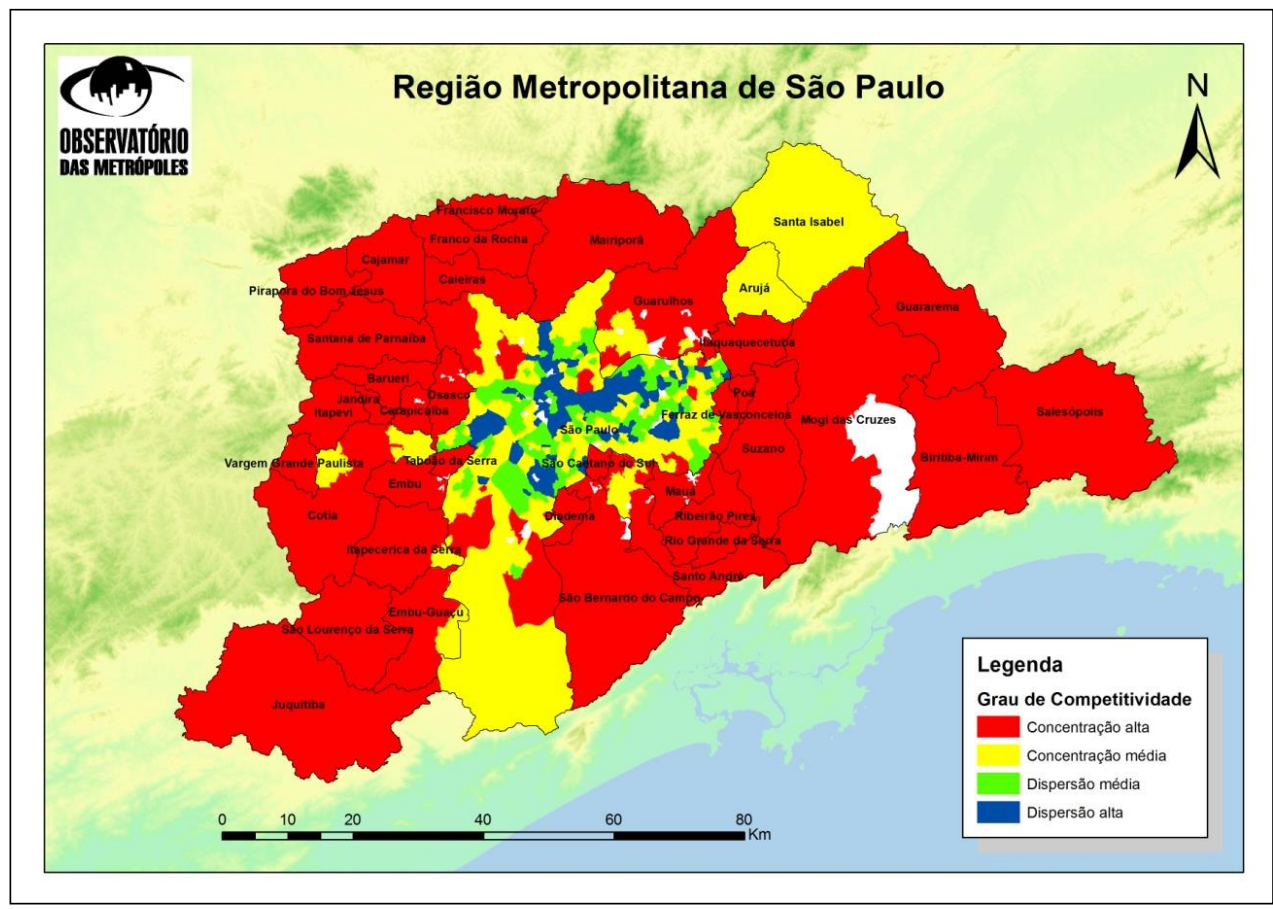

Fonte: Observatório das Metrópoles (2011).

Fica destacada no mapa a desigualdade no grau de concentração da disputa eleitoral na RMSP, em que as áreas classificadas como disputa eleitoral altamente concentrada (baixo NECm) correspondem aos municípios do entorno da capital, enquanto as áreas classificadas como de dispersão alta estão circunscritas nas áreas mais centrais da cidade de São Paulo. Assim, se considerarmos a existência de um "efeito metrópole" sobre o NECm, os dados apontam que esse efeito parece ser maior quanto mais central for a unidade de análise dentro da metrópole.

Em função da falta de disponibilidade de dados sobre as "áreas de ponderação" utilizadas, não foi possível realizar uma investigação de outros fatores que poderiam se correlacionar com o NECm. Além disso, é importante salientar que, em uma análise que pretenda capturar a magnitude do "efeito metrópole" nos locais de votação, o ideal seria utilizar áreas de ponderação de todo o estado ou, pelo menos, incluir uma parte dele com municípios não metropolitanos, uma vez que, ainda que em diferentes magnitudes, o "efeito metrópole" parece incidir sobre todos os municípios metropolitanos. É preciso considerar ainda que muitas variáveis socioeconômicas e demográficas utilizadas em modelos que pretendem compreender sua relação com o grau de concentração da disputa eleitoral possuem uma alta correlação com o nível de centralidade metropolitana. 
No modelo apresentado, a concentração da disputa eleitoral medida pelo NECm parece ser influenciada por variáveis relativas ao próprio processo eleitoral e por um "efeito metrópole", que faz com que os municípios metropolitanos apresentem uma disputa menos concentrada. Os mecanismos que atuam nesse "efeito metrópole" são diversos e parecem influenciar diferentes processos dentro do espaço metropolitano. Nunes, Chaia e Sanches (2012) levantam algumas possibilidades, como níveis mais elevados de socialização, interesse pela política, associativismo, mobilização e exposição à mídia e similares.

Outra possibilidade é que esse possível "efeito metrópole" esteja relacionado ao perfil dos deputados eleitos por essas regiões, mais propensos a um comportamento legislativo de natureza universalista, em que as questões metropolitanas teriam mais chances de aparecer e evoluir, ainda que os dados apresentados não permitam afirmar que essas diferenças no nível de concentração da disputa eleitoral de fato influenciam o comportamento legislativo dos deputados.

\section{Análise da competitividade da disputa eleitoral medida pelo índice $T$}

Esta seção caracteriza a disputa eleitoral nos municípios paulistas a partir do cálculo do índice T, proposto por Silva (2013). O Gráfico 3 mostra as médias do índice T para a capital paulista e as demais RMs do estado nos pleitos de 2002, 2006 e 2010 :

\section{Gráfico 3}

Evolução do índice T para as eleições a deputado estadual de São Paulo, 2002, 2006, 2010

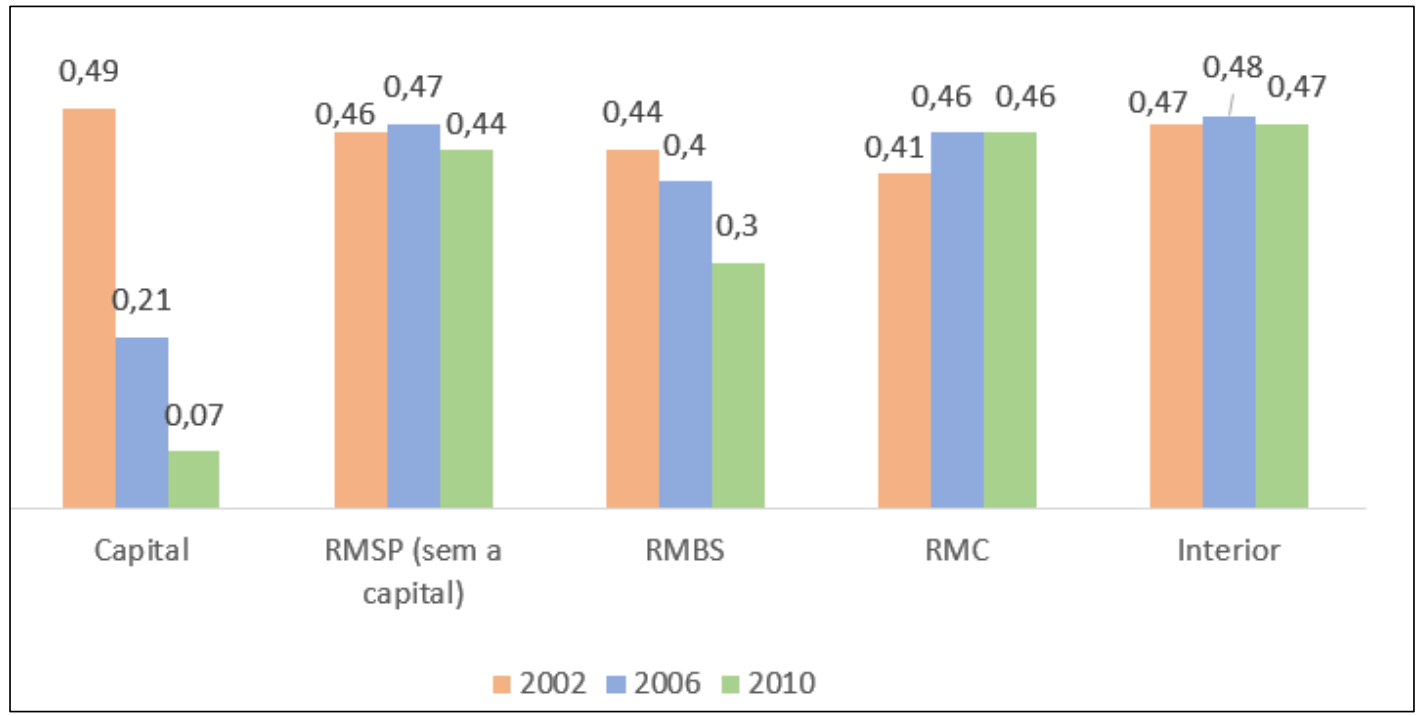

Fonte: Elaboração própria a partir dos dados do TRE-SP. 
Observa-se que os municípios do interior apresentam uma menor competitividade eleitoral, com exceção de 2002, quando a capital paulista apresenta um índice acima da média em função da votação atípica na candidata do Prona, como anteriormente assinalado. Nos anos de 2006 e 2010, o índice da capital fica bem abaixo da média, especialmente em 2010, indo ao encontro dos achados de Silva (2013), que apontam que as capitais tendem a ter uma disputa eleitoral mais competitiva. O resultado de 2002 , no entanto, aponta que essa competitividade é sensivelmente influenciada pelo contexto político.

O restante dos municípios da RMSP (sem a capital) apresenta um índice de competitividade próximo da média geral nos três pleitos analisados, enquanto a RMBS apresenta a disputa mais competitiva em 2006 e 2010, considerando as RMs analisadas.

Observa-se ainda que não é possível identificar um padrão de evolução do índice entre os pleitos analisados: na capital e na RMBS, o índice apresenta uma tendência de queda; na RMSP sem a capital e no interior, o índice aumenta de 2002 para 2006 e torna a cair em 2010, e, na RMC, o índice sobe de 2002 para 2006 e se mantém estável em 2010. A variabilidade do índice entre os pleitos nos diferentes grupos de municípios analisados parece indicar novamente a importância da influência dos fatores relativos ao contexto político, e as distintas trajetórias do índice dentro desses grupos parecem indicar que esses fatores são relativos, sobretudo, a um contexto político local.

\section{Fatores que influenciam a competitividade da disputa eleitoral medida pelo índice $T$}

Para uma melhor compreensão da disputa eleitoral metropolitana dentro dos termos analisados, optou-se por replicar o modelo de regressão múltipla já utilizado para o NECm, a fim de testar se a diferença na competitividade da disputa eleitoral entre as regiões é significativa e se a variação do índice $\mathrm{T}$ está correlacionada com variáveis socioeconômicas dos municípios. Embora os dados apontem a importância da influência de fatores do contexto político local sobre a competitividade eleitoral, não foi possível mensurar nenhuma variável que sintetizasse esses fatores.

As variáveis que compõem o modelo são PIB, taxa de analfabetismo na população com mais de 25 anos (T_ANALF25) e taxa de urbanização (T_URB), pois foram as que apresentaram correlação significativa com a taxa de competitividade medida pelo índice $T$ (tabela no Apêndice 2), e não apresentaram alta correlação entre si.

A forma funcional do modelo estatístico de regressão múltipla com as variáveis selecionadas mais as variáveis binárias (dummies) relativas à capital e às RMs é dada pela expressão:

$$
\begin{aligned}
T_{m t}=\beta_{1}+\beta_{2} T_{-} & A N A L F 25_{m t}+\beta_{3} P_{I B} B_{m t}+\beta_{4} T_{-} U R B_{m t}+\beta_{5} \text { DummyCapital }+\beta_{6} \text { DummyRMSP } \\
& +\beta_{7} \text { DummyRMCBS }+\beta_{8} \text { Dummy } 2006+\beta_{9} \text { Dummy } 2010
\end{aligned}
$$


em que a variável dependente do modelo é o índice T do município $m$ no ano eleitoral $t$. Os resultados das estimativas estão na Tabela 6:

\section{Tabela 6}

Estimativas dos parâmetros do modelo de regressão múltipla para o índice $T$ como variável dependente

\begin{tabular}{|c|c|c|}
\hline \multicolumn{3}{|c|}{ Índice $\mathbf{T}$} \\
\hline & Modelo 1 & Modelo 2 \\
\hline C & $\begin{array}{c}0,53 * * * \\
(0,48)\end{array}$ & $\begin{array}{c}0,54 * * * \\
(0,48)\end{array}$ \\
\hline PIB & $\begin{array}{c}-1,954 \mathrm{E}-9 * * * \\
(0,00)\end{array}$ & $\begin{array}{c}-9,518 \mathrm{E}-9 * * * \\
(0,00)\end{array}$ \\
\hline T_ANALF_25 & $\begin{array}{c}-0,005 * * * \\
(0,002)\end{array}$ & $\begin{array}{c}-0,006 * * * \\
(0,002)\end{array}$ \\
\hline T_URB & $\begin{array}{c}0,00 \\
(0,00)\end{array}$ & $\begin{array}{c}0,00 \\
(0,00)\end{array}$ \\
\hline Dummy_Capital & & $\begin{array}{l}1,38 * * \\
(0,59)\end{array}$ \\
\hline Dummy_RMSP & & $\begin{array}{l}-0,24 \\
(0,23)\end{array}$ \\
\hline Dummy_RMCBS & & $\begin{array}{c}-0,72 * * * \\
(0,026)\end{array}$ \\
\hline Dummy_2006 & $\begin{array}{c}0,002 \\
(0,013)\end{array}$ & $\begin{array}{l}-0,001 \\
0,013\end{array}$ \\
\hline Dummy_2010 & $\begin{array}{c}-0,26 * * \\
(0,14)\end{array}$ & $\begin{array}{c}-0,033^{* *} \\
(0,14)\end{array}$ \\
\hline $\mathrm{R}^{2}$ & 0,011 & 0,02 \\
\hline No de observações & 1935 & 1935 \\
\hline
\end{tabular}

Fonte: Elaboração própria a partir dos dados do TRE-SP e do Atlas de Desenvolvimento Humano - PNUD 2010.

Erros-padrão entre parênteses. $* * * \mathrm{p}<0,01, * * \mathrm{p}<0,05, * \mathrm{p}<0,10$.

Primeiramente, os resultados mostram que os modelos especificados apresentam um $\mathrm{R}^{2}$ muito baixo, ou seja, explicam muito pouco a variação da competitividade nos municípios. O PIB apresenta uma relação negativa e significativa com o índice: quanto maior o PIB, menor o índice $\mathrm{T}$ e, portanto, maior a competitividade. Com uma relação igualmente negativa com o índice $\mathrm{T}$, a taxa de analfabetismo apresenta um resultado contraintuitivo, pois, quanto maior a taxa de analfabetismo, maior a competitividade. No entanto, com as informações disponíveis e o baixo poder explicativo das variáveis, não é 
possível tecer hipóteses a respeito. A taxa de urbanização não apresenta correlação com o índice, ao contrário do esperado de acordo com a literatura da área.

No modelo 2, as variáveis binárias (dummies) relativas à capital e às RMs aumentam um pouco o $\mathrm{R}^{2}$ e são significativas para os casos da capital e das regiões metropolitanas de Campinas e da Baixada Santista. No entanto, a correlação com a dummy da capital é positiva (maior o índice, portanto menor a competitividade), o que vai de encontro com os resultados achados por Silva (2013), que mostram que as capitais tendem a apresentar um nível de competitividade eleitoral maior do que a média. Esse resultado parece estar fortemente influenciado pelo alto índice $T$ da capital no ano de 2002, como anteriormente ressaltado. No caso da dummy_RMCBS, embora a relação com o índice seja negativa, apontando uma maior competitividade eleitoral nesses municípios, essa correlação não ocorre para o caso da RMSP, não havendo indícios suficientes para apontar um "efeito metrópole" sobre o índice $T$, ou seja, não parece haver nenhuma relação entre a competitividade da disputa eleitoral em um município e o fato de o município pertencer a uma região metropolitana.

Finalmente, a dummy_2010 também apresenta uma relação negativa e significativa com o índice, o que indica uma eleição mais competitiva nesse ano.

Portanto, a análise da competitividade da disputa eleitoral paulista medida pelo índice $\mathrm{T}$ não mostrou correlações significativas com as características dos municípios, parecendo ser influenciada, sobretudo, por fatores do contexto político-eleitoral. Assim, os resultados não oferecem indícios para uma maior compreensão entre a representação política e a evolução de uma agenda metropolitana na Assembleia Paulista.

\section{Conclusões}

Este artigo procurou analisar a tese de Carvalho e Ribeiro (2013) de que a ausência de temas de natureza metropolitana na agenda política se deve, em parte: i) à subrepresentação de deputados de base geográfica metropolitana na Câmara e nas Assembleias, considerando que esses deputados tendem a ter um comportamento legislativo voltado para temas de natureza universalista, em que questões como a governança e a gestão metropolitana se inserem; e ii) ao comportamento político das metrópoles, que seria regulado por gramáticas políticas distintas, com a capital marcada por uma disputa mais competitiva e politizada, enquanto a periferia metropolitana se caracterizaria por uma disputa pouco competitiva marcada pelo voto personalizado.

Os dados analisados mostraram que a sub-representação de deputados metropolitanos no Legislativo estadual, verificada na maioria das regiões metropolitanas do país em outros estudos, não ocorre no caso da RMSP, que possui uma representação na Assembleia mais do que proporcional ao seu número de eleitores.

A análise do comportamento político das metrópoles foi realizada a partir do nível de concentração e competitividade da disputa eleitoral, e os resultados encontrados 
também não permitem colocar esse fator como um obstáculo à efetivação de uma agenda metropolitana no estado. Primeiramente, o cálculo do número efetivo de candidatos por município (NECm) utilizado para medir o grau de concentração da disputa eleitoral mostrou que a capital paulista apresenta uma disputa bem menos concentrada que a do restante dos municípios metropolitanos, mas esses municípios também apresentam uma disputa eleitoral menos concentrada do que a do restante dos municípios do interior do estado. Ou seja, nesses locais um número maior de candidatos recebe um número expressivo de votos, aumentando as chances de que candidatos com agendas mais universalistas, em que as questões metropolitanas estariam inseridas, sejam eleitos. Os modelos mostraram ainda que a pouca ou nula correlação do nível de concentração da disputa eleitoral com variáveis socioeconômicas sugere a existência de um "efeito metrópole" sobre esse indicador.

Já a competitividade da disputa eleitoral, medida a partir do cálculo do índice $T$, não mostrou relação com o nível de urbanização nem com o fato de o município pertencer a uma região metropolitana. Mesmo a capital paulista não apresenta um nível de competitividade significantemente mais alto do que o restante dos municípios. Os dados mostram ainda que não há uma relação definida entre competitividade e concentração da disputa medida através desses índices. Ou seja, um número expressivo de municípios apresenta uma alta concentração da disputa ao mesmo tempo que esta se mostra competitiva e vice-versa.

Portanto, o "efeito metrópole" verificado para o caso do NECm não ocorre para o caso do índice $T$, em que os dados não mostram diferenças significativas entre a competitividade dos municípios metropolitanos e a dos municípios do interior. Esse fato parece se dar em função dos fatores relacionados ao contexto político que, dentro do nosso sistema eleitoral, teriam um efeito definidor sobre a competitividade da disputa, como ilustrou o caso da deputada Havanir em 2002.

Os dados analisados não permitem afirmar que a ausência desses fatores no campo político-eleitoral se traduza em uma vantagem do estado de São Paulo para a efetivação de uma agenda metropolitana; porém, o estudo de Padilha, Ribeiro e Carvalho (2019), a partir da análise da atividade legislativa das proposições de projetos de lei dos deputados paulistas, mostrou que, de fato, os deputados de base metropolitana tendem a apresentar mais projetos de natureza universalista do que seus pares que possuem sua base geográfica de votação no interior do estado, incluindo aí temas de natureza metropolitana.

A literatura sugere que um ambiente onde a disputa eleitoral é pouco concentrada tende a ser mais politizado e, portanto, propenso a eleger deputados mais direcionados a questões de natureza universalista, como a questão da governança metropolitana aqui considerada. As análises realizadas neste artigo apontam que, além de uma quantidade proporcional de deputados metropolitanos na Alesp, o caso da RMSP mostra a existência de um "efeito metrópole" sobre a concentração da disputa eleitoral nos municípios 
FREDERICA VALLE DE QUEIROZ PADILHA

metropolitanos (disputa menos concentrada nesses municípios), indicando um ambiente político-eleitoral em que uma agenda metropolitana teria mais chances de avançar.

\section{Referências bibliográficas}

AMES, B. Os entraves da democracia no Brasil. Rio de Janeiro: Fundação Getúlio Vargas, 2003.

AtLAS de Desenvolvimento Humano do Brasil de 2010. "PNUD - Programa das Nações Unidas para o Desenvolvimento". Disponível em: <http://www.atlasbrasil.org.br/>. Acesso em: maio 2016.

Avelino, G.; Biderman, C.; Silva, G. "A concentração eleitoral nas eleições paulistas: medidas e aplicações". Dados - Revista de Ciências Sociais, Rio de Janeiro, vol. 54, no 2, p. 319-347, 2011.

AYDos, E. D. O voto distrital e o aperfeiçoamento da democracia representativa no Brasil. Mimeo, Porto Alegre, 1979.

CARVALho, N. R. E no início eram as bases: geografia política do voto e comportamento legislativo no Brasil. Rio de Janeiro: Editora Revan, 2003.

. "Geografia política das eleições congressuais: a dinâmica de representação das áreas urbanas e metropolitanas no Brasil". Cadernos Metrópole, São Paulo, vol. 11, no 22, p. 367-384, jul.-dez. 2009.

. Geografia política das eleições congressuais: a dinâmica da representação das áreas urbanas e metropolitanas do Brasil. In: AZEVEDO, S.; RiBEIRO, L. C. Q.; SANTOS JuniOR, O. A. (orgs.). Cultura política, cidadania e voto: desafios para governança metropolitana. Rio de Janeiro: Letra Capital, 2012.

CARVALHO, N. R.; CORRÊA, F. S. É possível o paroquialismo metropolitano? Organização socioespacial metropolitana e a competitividade por votos nas eleições proporcionais na RMRJ. In: AZEVEDO, S.; Ribeiro, L. C. Q.; SANTOS Junior, O. A. (orgs.). Cultura política, cidadania e voto: desafios para governança metropolitana. Rio de Janeiro: Letra Capital, 2012.

Carvalho, N. R.; Ribeiro, L. C. Q. "Représentation et atrophie politiques des métropoles: le cas du Brésil". Sociologie et Sociétés, vol. 45, n² 2, p. 293-319, 2013.

DAHL, R. Polyarchy: participation and opposition. Yale University Press: New Haven, 1971.

DIAS, J. L. M. Legislação eleitoral e padrões de competição político-partidária. In: LIMA JR., O. (org.). Sistema eleitoral brasileiro: teoria e prática. Rio de Janeiro: Iuperj/Rio Fundo Editora, p. 65-98, 1991.

DUVERGER, M. Les partis politiques. Paris: Armand Colin, 1951.

FERnANDES, E. Apresentação. In: Gouvêa, R. A questão metropolitana no Brasil. Rio de Janeiro: Editora FGV, 2005.

Figueiredo, A.; Limongi, F. Política orçamentária no presidencialismo de coalizão. Rio de Janeiro: Ed. FGV, 2008.

iBge - Instituto Brasileiro de Geografia e Estatística. Pesquisa nacional por amostra de domicílios: síntese de indicadores. Rio de Janeiro: IBGE, 2015.

LAAKSO, M.; TAAgePERA, R. "Effective number of parties: a measure with application to West Europe". Comparative Political Studies, vol. 12, p. 3-27, Apr. 1979. 
LAMOUNIER, B. "A representação proporcional no Brasil: mapeamento de um debate". Revista de Cultura e Política, São Paulo, no 7, 1982.

LIPSET, S. M. O homem político. Rio de Janeiro: Zahar, 1967.

Nicolau, J. M.; SCHMITT, R. A. "Sistema eleitoral e sistema partidário". Lua Nova, Rio de Janeiro, no 36, p. 129-147, 1995.

NUNES, E.; CHAIA, V.; SANCHES, F. Cultura política e valores de cidadania na Região Metropolitana da São Paulo. In: AzeVedo, S.; Ribeiro, L. C. Q.; SANTos Junior, O. A. (orgs.). Cultura política, cidadania e voto: desafios para governança metropolitana. Rio de Janeiro: Letra Capital, 2012.

OBSERVATÓRIO DAS METRÓPOlES. "Geografia do voto para deputados estaduais nas áreas intraurbanas da Região Metropolitana de São Paulo". Relatório do projeto de pesquisa Localismos, Geografia Social do Voto e Governança Metropolitana. Rio de Janeiro, 2011 (não publicado).

Disponível em:

. "Arranjos Institucionais para a gestão metropolitana". Relatório de Pesquisa, 2009.

<http://www.observatoriodasmetropoles.ufrj.br/relatorio_arranjos_gestao_metropolitana.pdf >. Acesso em: 13 maio 2016.

Padilha, F. V. Q.; Ribeiro, L. C. Q.; CARValho, N. "Representação política e governança na Região Metropolitana de São Paulo". Anais Congresso Observatório das Metrópoles 20 Anos. Rio de Janeiro: IPPUR - UFRJ, 2019.

RIBEIRO, L. C. Q. As metrópoles e a sociedade brasileira: futuro comprometido? In: RIBEIRO, L. C. (org). Metrópoles: entre a coesão e a fragmentação, a cooperação e o conflito. Rio de Janeiro: Letra Capital, 2004.

SAmuels, D. Ambition, federalism, and legislative politics in Brazil. Cambridge: Cambridge University Press, 2003.

SILVA, G. P. "Uma avaliação empírica da competição eleitoral para a Câmara Federal no Brasil". Opinião Pública, Campinas, vol. 19, no 2, nov. 2013.

SOARES, G. A. D. "Desigualdades eleitorais no Brasil". Revista de Ciência Política, vol. 7, nº 1, p. 25-48, 1973. . A democracia interrompida. Rio de Janeiro: Ed. FGV, 2001.

TAAGeperA, R. "Inequality, concentration, imbalance". Political Methodology, p. 275-291, 1979. 


\section{Apêndice 1}

Correlações entre variáveis socioeconômicas dos municípios e o NECm

\begin{tabular}{|c|c|c|c|c|c|c|c|}
\hline & NECm & POP & T_ANALF25 & GINI & RDPC & T_URB & PIB \\
\hline $\mathrm{NECm}$ & 1 & & & & & & \\
\hline POP & 0,621 & 1 & & & & & \\
\hline T_ANALF25 & $\overline{-}^{-}, 094^{* *}$ & $\begin{array}{c}- \\
157^{* *}\end{array}$ & 1 & & & & \\
\hline Gini &, $108^{* *}$ &, $131^{* *}$ & 019 & 1 & & & \\
\hline RDPC &, $143^{* *}$ & $246^{* *}$ &,$- 757^{* *}$ &, $211^{* *}$ & 1 & & \\
\hline T_URB &, $173^{* *}$ & $103^{* *}$ &, $393^{* *}$ &,- 028 &, $170^{* *}$ & 1 & \\
\hline PIB &, $621^{* *}$ & ,992** &,$- 139^{* *}$ & $128^{* *}$ &, $245^{* *}$ & ,097** & 1 \\
\hline
\end{tabular}

Fonte: Elaboração própria com base em dados do TRE.

**A correlação é significativa no nível 0,01 (bilateral).

Números no fundo cinza = variáveis com alta correlação, de modo que só uma pode ser usada no modelo.

\section{Apêndice 2}

Correlações entre variáveis socioeconômicas dos municípios e o índice T

\begin{tabular}{|l|c|c|c|c|c|c|}
\hline & POP & T_ANALF25 & GINI & RDPC & T_URB & PIB \\
\hline Índice T & $-0,44$ & $-0,067 * *$ & 0,026 & 0,023 & $0,046 *$ & $-0,049 *$ \\
\hline
\end{tabular}

Fonte: Elaboração própria a partir dos dados do TRE-SP.

\section{Abstract}

Electoral disputes and political representation in the Metropolitan Region of São Paulo

This article analyzes how the dynamic of representation policy can translate into obstacles for the mobilization of the Legislative political actors around a metropolitan agenda. The objective is to analyze the representativeness of metropolitan - based deputies in the Legislative Assembly of the State of São Paulo - and to characterize the electoral dispute in the state municipalities, which will be characterized by two different indicators: a concentration of the dispute (effective number of candidates) and an electoral competitiveness index ( $T$ index). The results show that the metropolitan deputies of São Paulo are not underrepresented in the Assembly and the electoral dispute in metropolitan municipalities tends to be less concentrated, with a "metropolis effect" on the concentration of the dispute, but not necessarily more competitive.

Keywords: electoral dispute; political representation; metropolitan governance; effective number of candidates; $T$ index

\section{Resumen}

Disputa electoral y representación política en la Región Metropolitana de São Paulo

Este artículo analiza cómo la dinámica política de representación puede traducirse en obstáculos para la movilización de los actores políticos del Legislativo en torno a una agenda metropolitana. El objetivo 
es analizar la representatividad de los diputados de base metropolitana en la Asamblea Legislativa de São Paulo y caracterizar la disputa electoral en los municipios paulistas, que se caracterizará a partir de dos diferentes indicadores: un de concentración (número efectivo de candidatos) y un de competitividad (índice T). Los resultados apuntan que los diputados metropolitanos paulistas no son subrepresentados en la Asamblea y la disputa electoral en los municipios metropolitanos tiende a ser menos concentrada, con un "efecto metrópoli" sobre la concentración de la disputa, pero no necesariamente más competitiva.

Palabras clave: disputa electoral; representación política; gobernanza metropolitana; número de candidatos efectivos; índice T

\section{Résumé}

Dispute électoral et représentation politique dans la Région Métropolitaine de São Paulo

Cet article analyse comment la dynamique de la politique de représentation peut se traduire par des obstacles à la mobilisation des acteurs politiques législatifs autour d'un agenda métropolitain. L'objectif de cet article est d'analyser la représentativité des députés métropolitains à l'Assemblée législative de I'État de São Paulo et de caractériser le dispute électoral dans les municipalités de l'etát, qui sera caractérisé par deux indicateurs différents: un de concentration (nombre effectif de candidats) et un de compétitivité (indice T). Les résultats montrent que les députés métropolitains de São Paulo ne sont pas sous-représentés dans l'Assemblée et que les élections dans les municipalités métropolitaines ont tendance à être moins concentrées, avec un "effet de métropole" sur la concentration de la dispute, mais pas nécessairement plus compétitives.

Mots-clés: dispute électoral; représentation politique; gouvernance métropolitaine; nombre effectifs de candidats; index T

Artigo submetido à publicação em 14 de abril de 2019. Versão final aprovada em 13 de maio de 2020.

Opinião Pública adota a licença Creative Commons CC-BY. 